\title{
Influence of Cryorolling on the Precipitation of Cu-Ni-Si Alloys: An In Situ X-ray Diffraction Study
}

\author{
Wei Wang ${ }^{1} \cdot$ Zong-Ning Chen $^{1} \cdot$ En-Yu Guo ${ }^{1} \cdot$ Hui-Jun Kang ${ }^{1} \cdot \mathrm{Yi} \mathrm{Liu}^{2} \cdot$ Cun-Lei Zou $^{1} \cdot$ Ren-Geng Li ${ }^{1} \cdot$ \\ Guo-Mao Yin ${ }^{1} \cdot$ Tong-Min Wang ${ }^{1}$
}

Received: 30 March 2018/Revised: 29 May 2018/Published online: 11 July 2018

(C) The Chinese Society for Metals and Springer-Verlag GmbH Germany, part of Springer Nature 2018

\begin{abstract}
The effect of cryorolling on the precipitation process of deformed $\mathrm{Cu}-\mathrm{Ni}$-Si alloys was investigated through in situ synchrotron X-ray diffraction technique. The results demonstrate that the precipitation process is significantly accelerated by cryorolling. Cryorolling produces higher dislocation density, which provides more heterogeneous nucleation sites for $\mathrm{Ni}_{2} \mathrm{Si}$ precipitates, hence promotes precipitation. In the early stage of aging, the enhanced nucleation of precipitates accelerates the depletion of supersaturation, and finer precipitates are obtained. In addition, recrystallization is promoted as a result of high stored energy in the cryorolled $\mathrm{Cu}-\mathrm{Ni}-\mathrm{Si}$ alloys, which facilitates the formation of discontinuous precipitation in the late stage of aging.
\end{abstract}

Keywords Copper alloy $\cdot$ Cryogenic $\cdot$ Rolling $\cdot$ Aging precipitation $\cdot$ Synchrotron radiation $\cdot$ X-ray diffraction

\section{Introduction}

Copper alloys are widely used for applications in electrical industries due to the high electrical conductivity and thermal conductivity [1]. However, pure copper is quite soft and has to be strengthened before it is used as industrial materials. Considering the tradeoff between mechanical properties and electrical conductivity [2], precipitation strengthening is employed to minimize the reduction in electrical conductivity [3]. Various alloying elements, either single element like Be [4] and Ti [5], or combination of elements such as $\mathrm{Cr}$ and $\mathrm{Zr}$ [6] and $\mathrm{Ni}$ and $\mathrm{Si}$ [7], were added to promote the mechanical properties of copper alloys. Of all the precipitation strengthened copper alloys,

Available online at http://link.springer.com/journal/40195

Hui-Jun Kang

kanghuijun@dlut.edu.cn

1 Key Laboratory of Solidification Control and Digital Preparation Technology (Liaoning Province), School of Materials Science and Engineering, Dalian University of Technology, Dalian 116024, China

2 Shanghai Synchrotron Radiation Facility, Shanghai Institute of Applied Physics, Chinese Academy of Sciences, Shanghai 201204, China
$\mathrm{Cu}-\mathrm{Ni}-\mathrm{Si}$ system alloys stand out as a result of their ultrahigh strength and high electrical conductivity [8].

While yield strength as high as $\sim 1 \mathrm{GPa}$ has already been documented [9], researching efforts of this field have been made to meet the ever-increasing demand of industrial applications. To this end, severe plastic deformation (SPD) techniques are playing a rapidly expanding role. Equal channel angular pressing (ECAP) reduces the grain size of copper tube and increases the hardness significantly [10]. Accumulative roll bonding (ARB) for 5 cycles significantly reduces the grain size from 4 to $0.4 \mu \mathrm{m}$, as compared to cold rolling [11]. High-pressure torsion (HPT) after 10 turns can reduce the grain size to $200 \mathrm{~nm}$ with homogeneous grain structure [12]. Multi-axial forging (MAF) at cryogenic temperature is capable of developing fine equiaxed type dislocation substructures/subgrains, which results in 9 times improvement in the yield strength compared to that of the homogenized annealed sample [13]. Among the various methods, cryorolling stands out owing to the fact that other approaches are not only difficult or expensive to implement, but also difficult to keep free of artifacts such as porosity and impurities [14]. Cryorolling suppresses the dynamic recovery during rolling at liquid nitrogen temperature and stimulates deformation twinning, thereby enhancing the grain-refinement effect [15]. Cryorolling and subsequent aging is one of the most 
promising approaches for fabricating excellent balanced high strength and high electrical conductivity copper alloys in large-scale industrial application [16]. However, previous researches have been mainly focused on solid solution strengthened copper alloys like $\mathrm{Cu}-\mathrm{Zn}$ [17] and $\mathrm{Cu}-\mathrm{Al}$ alloys [18], few efforts are made to study the precipitation hardening $\mathrm{Cu}-\mathrm{Ni}-\mathrm{Si}$ alloys.

In this study, the effect of cryorolling on the precipitation process of $\mathrm{Cu}-\mathrm{Ni}-\mathrm{Si}$ alloys was investigated by in situ synchrotron X-ray diffraction technique in addition to traditional hardness and electrical conductivity curves. For comparison, the alloy was cryorolled (CR) at the liquid nitrogen temperature and room temperature rolled (RTR) at $298 \mathrm{~K}$, respectively.

\section{Experimental}

The designed alloys with a nominal composition of $2.0 \mathrm{wt} \% \mathrm{Ni}-0.5 \mathrm{wt} \% \mathrm{Si}$ were prepared by melting electrolytic copper, nickel (99.9 wt\%) and silicon (99.95 wt\%) with the protection of argon atmosphere. Graphite furnace and iron mold were used for the casting of ingots. The cast ingots were homogenized at $1233 \mathrm{~K}$ for $24 \mathrm{~h}$ before hot rolling at $1123 \mathrm{~K}$ with $50 \%$ reduction in thickness. The sheets were then solution treated at $1233 \mathrm{~K}$ for $1 \mathrm{~h}$ before rolled with $75 \%$ reduction in thickness. The sheets were rolled at room temperature $(293 \mathrm{~K})$ and liquid nitrogen temperature, respectively. For the rolling at liquid nitrogen temperature, the sheets were immersed in liquid nitrogen for $20 \mathrm{~min}$ before each pass.

A MH-50 type microhardness tester was employed for measuring microhardness with a load of $0.2 \mathrm{~kg}$ for $10 \mathrm{~s}$. The samples were mechanically ground and polished before testing. Five hardness tests were performed on each sample. A D60K digital electrical instrument was used to measure the electrical conductivity of samples. The international annealed copper standard (IACS) was used to present results of electrical conductivity tests. The microstructures were analyzed using a JSM-5600LV type of scanning electronic microscope (SEM) and Talos F200x field emission transmission electron microscope (TEM) with an accelerating voltage of $200 \mathrm{kV}$. Electron backscattered diffraction (EBSD) observations were performed on the longitudinal plane of aged samples after rolling, which contains both rolling direction (RD) and normal direction (ND). For EBSD analysis, the samples were mechanically ground and polished by $1 \mu \mathrm{m}$ diamond paste before vibration polishing. For EBSD characterization, the SUPRA55 field emission gun scanning electron microscope (FEG-SEM) equipped with the HKL EBSD system was used and the results were analyzed by HKL Channel 5 software. A misorientation threshold of $15^{\circ}$ was used to differentiate deformed grains and recrystallized grains.

The X-ray diffraction patterns were measured with a Mar225 CCD on the BL14B1 beamline of Shanghai Synchrotron Radiation Foundation (SSRF) [19]. The schematic of the setup for the in situ synchrotron diffraction experiments is shown in Fig. 1. Each sample with a thickness of $50 \mu \mathrm{m}$ was heated in a Linkam high-T chamber evacuated to $10^{-2} \mathrm{~Pa}$ at a heating rate of $20 \mathrm{~K} / \mathrm{min}$. Each type of sample was heated to $723 \mathrm{~K}$ and aged for $4 \mathrm{~h}$. The acquisition time for a single diffraction pattern was $1 \mathrm{~min}$. A $\mathrm{LaB}_{6}$ standard sample was used for calibration and the diffraction patterns were integrated using Fit2D software [20]. The full width at half maximum $\left(\mathrm{FWHM}=\left(\beta_{\mathrm{hkl}}\right)\right.$ measured) of peaks were corrected by the instrumental broadening $\left(\beta_{\mathrm{LaB} 6}\right)$. The corrected line broadening $\left(\beta_{\mathrm{hkl}}\right)$ can be obtained by [21]:

$\left.\beta_{\mathrm{hkl}}=\left[\left(\beta_{\mathrm{hkl}}\right)_{\text {measured }}^{2}-\beta_{\mathrm{LaB} 6}^{2}\right)\right]^{0.5}$.

According to the William-Hall method, the line broadening of peaks originates from the small crystallite size and strain [22]. Assuming the contributions of the two are independent, the line broadening can be expressed as

$\beta_{\mathrm{hkl}}=\frac{K \lambda}{\tau \cos \theta}+4 \varepsilon \tan \theta$.

where $K$ is the shape factor, $\lambda$ is the wavelength, $\tau$ is the effective crystallite size, $\theta$ is the Bragg angle and $\varepsilon$ is the root mean square value of microstrain. Thus the microstrain $\varepsilon$ can be obtained from the slope of the linear plot of $\beta_{\mathrm{hkl}} \cos \theta$ against $\sin \theta$, which will be used in the following discussion.

\section{Results and Discussion}

\subsection{Aging Behaviors}

Figure 2 illustrates the curves of Vickers hardness and electrical conductivity of $\mathrm{Cu}-\mathrm{Ni}-\mathrm{Si}$ alloys subjected to isochronal aging between 623 and $823 \mathrm{~K}$ for $1 \mathrm{~h}$ and isothermal aging at $723 \mathrm{~K}$ for various time. For the initial condition, the CR samples exhibit higher Vickers hardness and nearly identical electrical conductivity compared with that of the RTR samples, as shown in Fig. 2a, b. For isochronal aging, the hardness increases to the peak and decreases gradually thereafter, while the electrical conductivity value increases rapidly with increasing temperature before reaching a plateau at $748 \mathrm{~K}$. Cryorolling advances the peak value of hardness from 723 to $698 \mathrm{~K}$, and increases the electrical conductivity of $\mathrm{Cu}-\mathrm{Ni}-\mathrm{Si}$ alloys, especially at high temperatures. Similar results are 


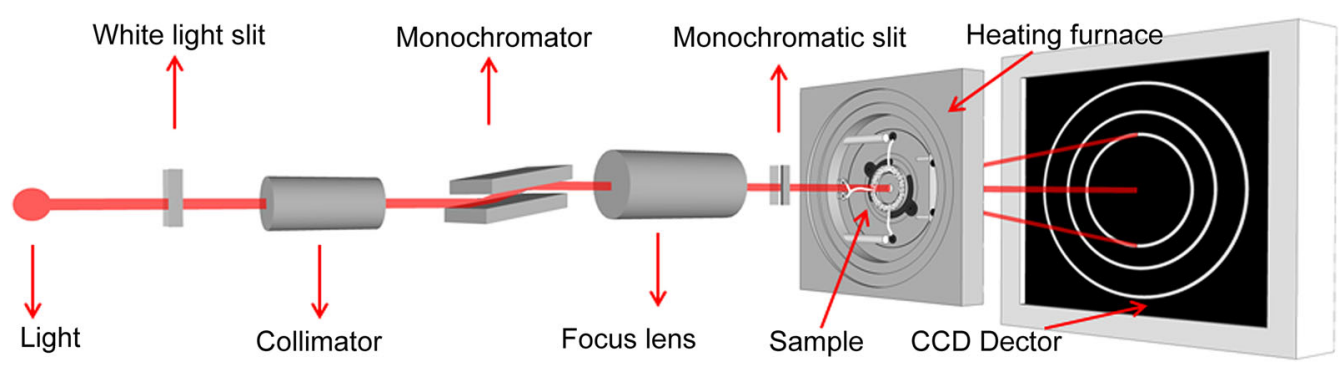

Fig. 1 Schematic of the setup for the in situ synchrotron diffraction experiments
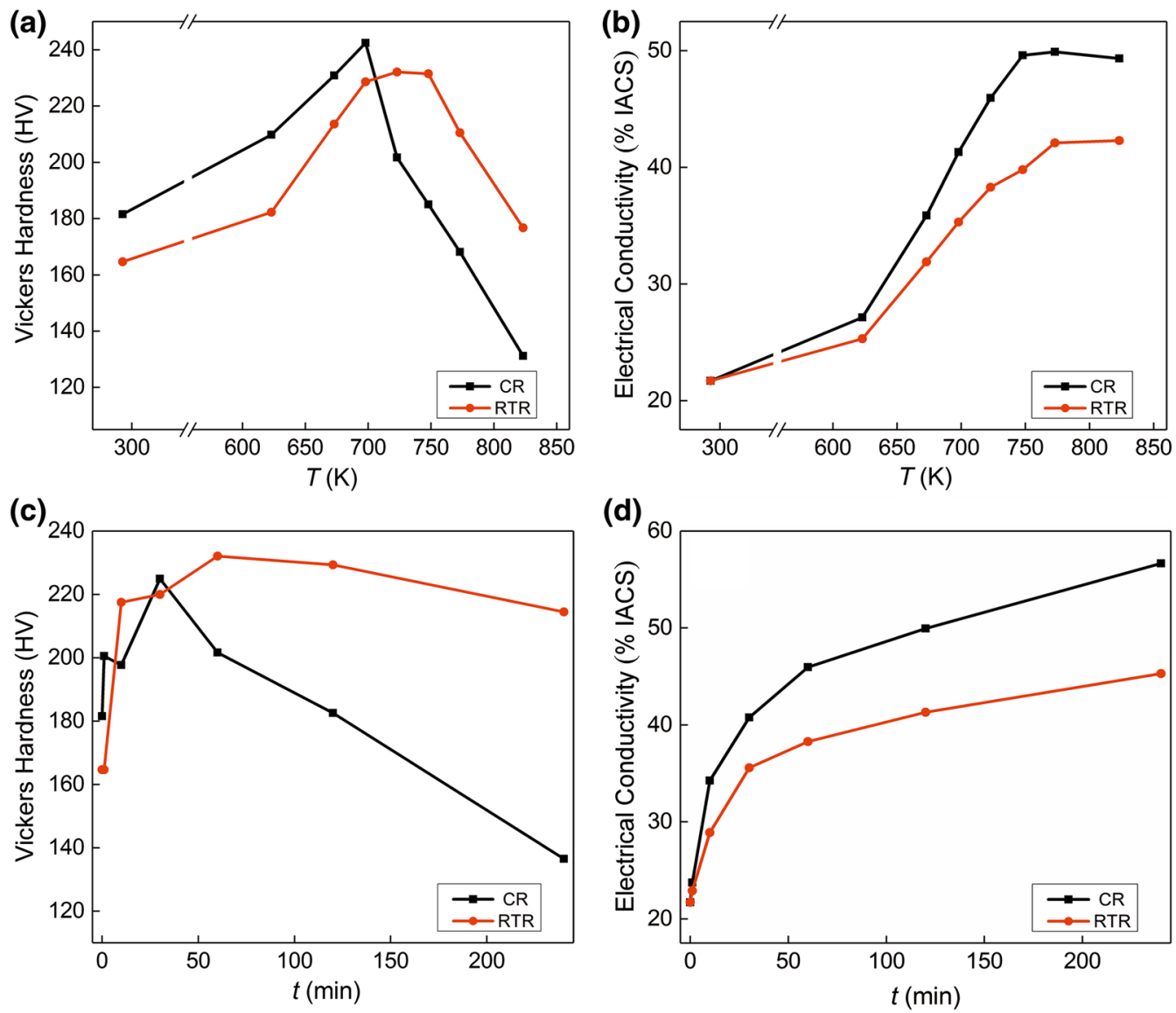

Fig. 2 Vickers Hardness and electrical conductivity curves of $\mathrm{Cu}-\mathrm{Ni}-\mathrm{Si}$ alloy subjected to isochronal aging for $1 \mathrm{~h} \mathbf{a}, \mathbf{b}$, isothermal aging $\mathbf{c}, \mathbf{d}$ at $723 \mathrm{~K}$ for various time

observed in the condition of isothermal aging (Fig. 2c, d). The peak value of hardness is achieved from 60 to $30 \mathrm{~min}$, and the electrical conductivity is obviously increased as well. When aged at $723 \mathrm{~K}$ for $240 \mathrm{~min}$, the electrical conductivity of cryorolled samples reaches $56.7 \%$ IACS, which is $25 \%$ higher than that of the room temperature rolled samples (45.3\% IACS).

According to the simplified Matthiessen's rule [23], the volume fraction of precipitates, $X$, can be deduced from the electrical conductivity, $C$, by the following equation

$C=C_{0}+\left(C_{\max }-C_{0}\right) \cdot X$. where $C_{0}$ is the electrical conductivity before aging treatment and $C_{\max }$ is the electrical conductivity at the end of aging treatment. The increase in the electrical conductivity reveals an accelerated precipitation process by cryorolling, which agrees well the hardness curves. It should be noted that with prolonging aging time, the reduction in dislocation density will inevitably increase the electrical conductivity. However, the influence of dislocation density on electrical conductivity is minor compared to that of solutes (the value of electrical conductivity is $22 \%$ IACS in 
solution-treated state and $21.7 \%$ IACS in both rolled states), and therefore reasonably neglected in the present study.

\subsection{In Situ Synchrotron Diffraction Results}

Figure 3 presents the results of in situ synchrotron diffraction experiments of $\mathrm{Cu}-\mathrm{Ni}-\mathrm{Si}$ alloy aged at $723 \mathrm{~K}$ for $4 \mathrm{~h}$. The pattern of cryorolled $\mathrm{Cu}-\mathrm{Ni}-\mathrm{Si}$ alloy aged for $60 \mathrm{~min}$ is drawn in Fig. 3a as an example of the diffraction patterns, where typical peaks of copper are observed and indexed. The enlarged magnifications illustrating minor precipitate peaks are shown in Fig. $3 \mathrm{~b}$, indicating the onset of precipitation during aging.

The variation of dislocation density during aging is presented in Fig. 3c, calculated from microstrain by the equation $\rho_{\mathrm{d}}=16.1 \varepsilon^{2} / b^{2}$ [24] , where $\rho_{\mathrm{d}}$ is the dislocation density and $b$ is the Burgers vector of copper matrix. For samples under both conditions, the dislocation density decreases with prolonging aging time. At the beginning of aging, the dislocation density of CR samples is higher than that of RTR samples. However, the reduction for dislocation density of CR samples is obviously faster than that of RTR samples. The dislocation density of CR samples
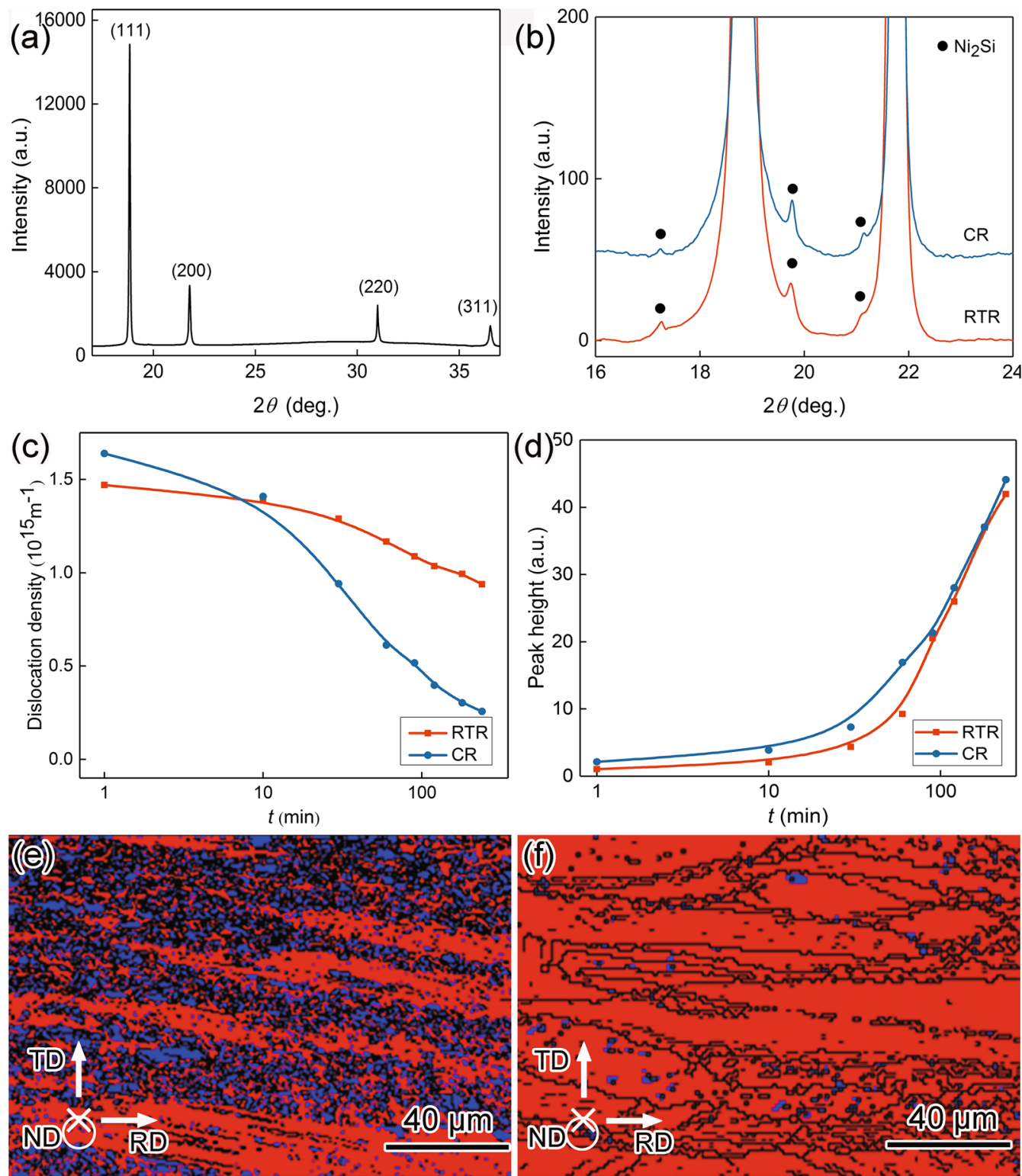

Fig. 3 Typical pattern of in situ synchrotron diffraction experiments of $\mathrm{Cu}-\mathrm{Ni}-\mathrm{Si}$ alloy aged at $723 \mathrm{~K}$ a, enlarged magnifications showing minor precipitate peaks $\mathbf{b}$; variation of dislocation densities $\mathbf{c}, \mathrm{Ni}_{2} \mathrm{Si}$ phase peak heights $\mathbf{d}$; selected portions of EBSD maps of $\mathrm{Cu}-\mathrm{Ni}-\mathrm{Si}$ alloys aged at $723 \mathrm{~K}$ for $2 \mathrm{~h}$ : e CR sample and f RTR sample. The recrystallized and deformed grains are colored blue and red, respectively; high-angle grain boundaries are depicted by black lines; RD, ND and TD are the rolling, normal, and transverse directions, respectively 
approaches to that of RTR samples at $10 \mathrm{~min}$, and is lower than that of RTR samples thereafter. The variation of dislocation density is closely associated with the recrystallization progress. As shown in Fig. 4, typical features of deformed copper alloys, such as dislocations and lamella structures, are observed in the RTR samples after aging for $2 \mathrm{~h}$ at $723 \mathrm{~K}$. However, in the CR samples, fewer dislocations can be detected and cross-annealing twins are observed in the coarse polygonal grains, demonstrating the onset of recrystallization process. EBSD analysis is utilized to better demonstrate the recrystallization process, as shown in Fig. 3e, f. The high-angle grain boundary (HAGB) spacing of lamellar grains is refined by cryorolling due to the suppression of dynamic recovery during rolling at liquid nitrogen temperature [15]. Recrystallized grains (grains coloring blue) are clearly observed in the CR sample, while deformed grains (grains coloring red) still dominate in the RTR sample. The recrystallized fractions are 44.9 and $2.7 \%$ for the CR sample and the RTR sample, respectively. Similar results have been reported earlier in pure copper subjected to cryorolling [25]. Precipitation takes place during aging, which has a restrained effect on the recrystallization process [26]. Considering precipitation, the driving force for recrystallization is expressed as a stored energy modified by a retarding Zener drag term [27]

$G=\frac{1}{2} \rho_{\mathrm{d}} \mu b^{2}-\frac{3 F_{\mathrm{v}} \gamma}{2 r}$.

where $\mu$ is the shear modulus of copper matrix, $F_{\mathrm{v}}$ is the volume fraction of precipitates, $\gamma$ is the interfacial energy and $r$ is the effective mean precipitate radius. The stored energy of deformed $\mathrm{Cu}-\mathrm{Ni}-\mathrm{Si}$ alloys is increased by cryorolling as a result of higher dislocation density. Zener pressure increases with the onset of precipitation at first and drops gradually upon precipitates coarsening during aging, and the dislocation density only affects the time to achieve the peak stress [27]. Therefore, cryorolling increases the driving force for recrystallization and the
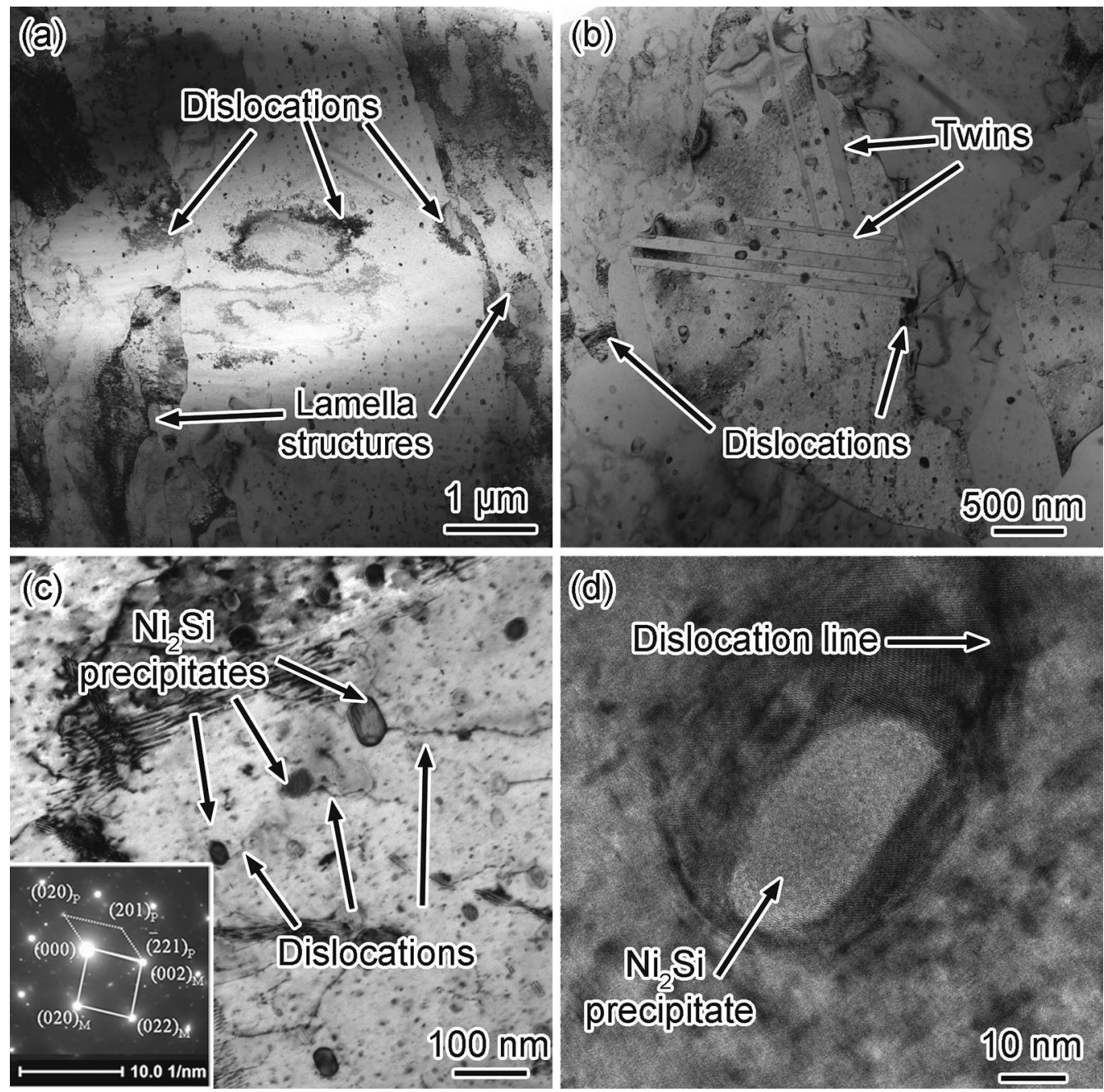

Fig. 4 Bright field TEM images of $\mathrm{Cu}-\mathrm{Ni}-\mathrm{Si}$ alloys aged at $723 \mathrm{~K}$ for $2 \mathrm{~h}$ : a RTR sample and b CR sample; $\mathbf{c}$ TEM image of cryorolled Cu-Ni$\mathrm{Si}$ alloy with selected area electron diffraction showing $\mathrm{Ni}_{2} \mathrm{Si}$ phase and $\mathbf{d}$ HRTEM image showing $\mathrm{Ni}_{2} \mathrm{Si}$ precipitate lying on dislocations 
annihilation of dislocations is enhanced as a result, which agrees well with the variation of dislocation densities.

Figure $3 \mathrm{~d}$ presents the variation of $\mathrm{Ni}_{2} \mathrm{Si}$ phase peak heights (the strongest peak at $2 \theta=19.5^{\circ}$,indexed as (121) or (301)), which can be used to qualitatively characterize the volume fraction of $\mathrm{Ni}_{2} \mathrm{Si}$ phase. The intensity of $\mathrm{Ni}_{2} \mathrm{Si}$ peak for the CR samples exceeds that of the RTR samples in the whole time period, indicating accelerated precipitation. The difference between the peak intensities of the CR and RTR samples is minor at the beginning, increases to the maximum at $60 \mathrm{~min}$, and decreases thereafter. The acceleration of precipitation by cryorolling occurs at the very beginning of aging, when nucleation dominates the precipitation process. The critical nucleation energy for heterogeneous nucleation is much lower than homogenous nucleation. Defects, such as dislocations and grain boundaries, are potential heterogeneous nucleation sites for precipitates. The contribution of grain boundaries is reasonably omitted because grain boundary precipitates account for less than $1 \%$ of all heterogeneous nucleation sites [28].

Figure $4 \mathrm{c}$ illustrates the location of precipitates found in the sample. The precipitates are identified as $\delta_{1}$-type $\mathrm{Ni}_{2} \mathrm{Si}$ phase existed in the early stages of aging, including peak aging in $\mathrm{Cu}-\mathrm{Ni}-\mathrm{Si}$ alloys [29]. High-resolution transmission electron microscope (HRTEM) image in Fig. 4d shows that elliptical $\mathrm{Ni}_{2} \mathrm{Si}$ particles are accompanied by dislocations, indicating a heterogeneous nucleation mechanism. Under the assumption of constant influx of solute atoms toward dislocations, where both the nucleation rate and particle size are constant, the nucleation rate can be given as [30]

$J=Z \beta^{*} \Psi \exp \left(\frac{-\Delta G_{n}}{k T}\right)$.

where $Z$ is the Zeldovich non-equilibrium factor, $\beta^{*}$ is the diffusion rate of solute atoms toward the critical nucleus, $\psi$ is the number density of nucleation sites and $G_{\mathrm{n}}$ is the formation energy of the nucleus. According to Russell [31], the term $\mathrm{Z} b *$ can be approximated as $D_{\text {pipe }} C_{\mathrm{S}} / a^{2}$, where $D_{\text {pipe }}$ is the diffusion coefficient of pipe diffusion through dislocations, $C_{\mathrm{S}}$ is the concentration of solute atoms and $a$ is the jump distance which equals to the lattice constant approximately. The density of nucleation site, $\psi$, can be approximated as $F \rho_{\mathrm{d}} / b$, where $F$ is an adjustable factor smaller than unity [27]. At the beginning of aging, the dislocation density of CR samples exceeds that of RTR samples (Fig. 3c). According to Eq. (5), the nucleation rate is improved by cryorolling, and the precipitation process is accelerated consequently.

\subsection{Precipitates}

Figure 5a, b presents dark-field TEM images of $\mathrm{Cu}-\mathrm{Ni}-\mathrm{Si}$ alloys aged at $723 \mathrm{~K}$ for $2 \mathrm{~h}$. Fine precipitates with the size of tens of nanometers can be observed. The distribution of precipitate size obtained from the dark-field TEM images is presented in Fig. 5c, d. The average precipitate diameters are $17.4 \pm 14.9 \mathrm{~nm}$ for RTR and $15.5 \pm 10.4 \mathrm{~nm}$ for CR samples, respectively. Typical morphologies of precipitates (marked by the white circles) are shown in Fig. 5e, f, which further validate the refining effect of cryorolling on $\mathrm{Ni}_{2} \mathrm{Si}$ precipitates in the early stage of aging. Moiré fringes are observed in both cases, indicating semi-coherent interfaces.

For the coarsening of precipitates, the role of dislocations is crucial. For supersaturated materials, the supersaturation remains unchanged in the initial stage of nucleation and growth, and undergoes a downward transient until a relatively small number of nodules become large enough to deplete the supersaturation significantly [32]. As discussed above, the nucleation of precipitates is promoted by cryorolling, which accelerates the downward transient of supersaturation of solutes. As a result, the lowered level of supersaturation reduces the driving force for solutes migration and suppresses the coarsening of precipitates. Moreover, the dislocations can act as fast paths for diffusing atoms, which is thought to originate from the disordered core region of dislocations that lowers the activation energy for diffusion [33]. For the cryorolled samples, recrystallization is promoted and the dislocation density is reduced to a lower value during aging compared to that of the room temperature rolled samples. The precipitates are no longer connected by the short-circuit diffusion paths offered by the dislocations, which also contributes to the hindered coarsening of precipitates in cryorolled $\mathrm{Cu}-\mathrm{Ni}-\mathrm{Si}$ alloys during aging.

In the late stage of aging, the flux contribution from the dislocation cores can be reasonably neglected due to the fact that the supersaturation of the entire matrix is of the interest in this work, while the supersaturation in the dislocation lines only represents a small fraction of the total. Under the assumption of one-dimensional diffusion down the dislocations, the solutes concentration in the dislocation pipe regions saturates to the equilibrium concentration while solute flux from the bulk is still occurring [34]. Thus the growth of precipitates lying on dislocations is controlled by bulk diffusion rather than pipe diffusion. Herein the asymptotic growth for the average radius of coarsening of continuous precipitates lying on dislocations is given by [34]

$\bar{R}^{3}=\frac{4}{9} \alpha \Omega D C_{\mathrm{e}} t$. 

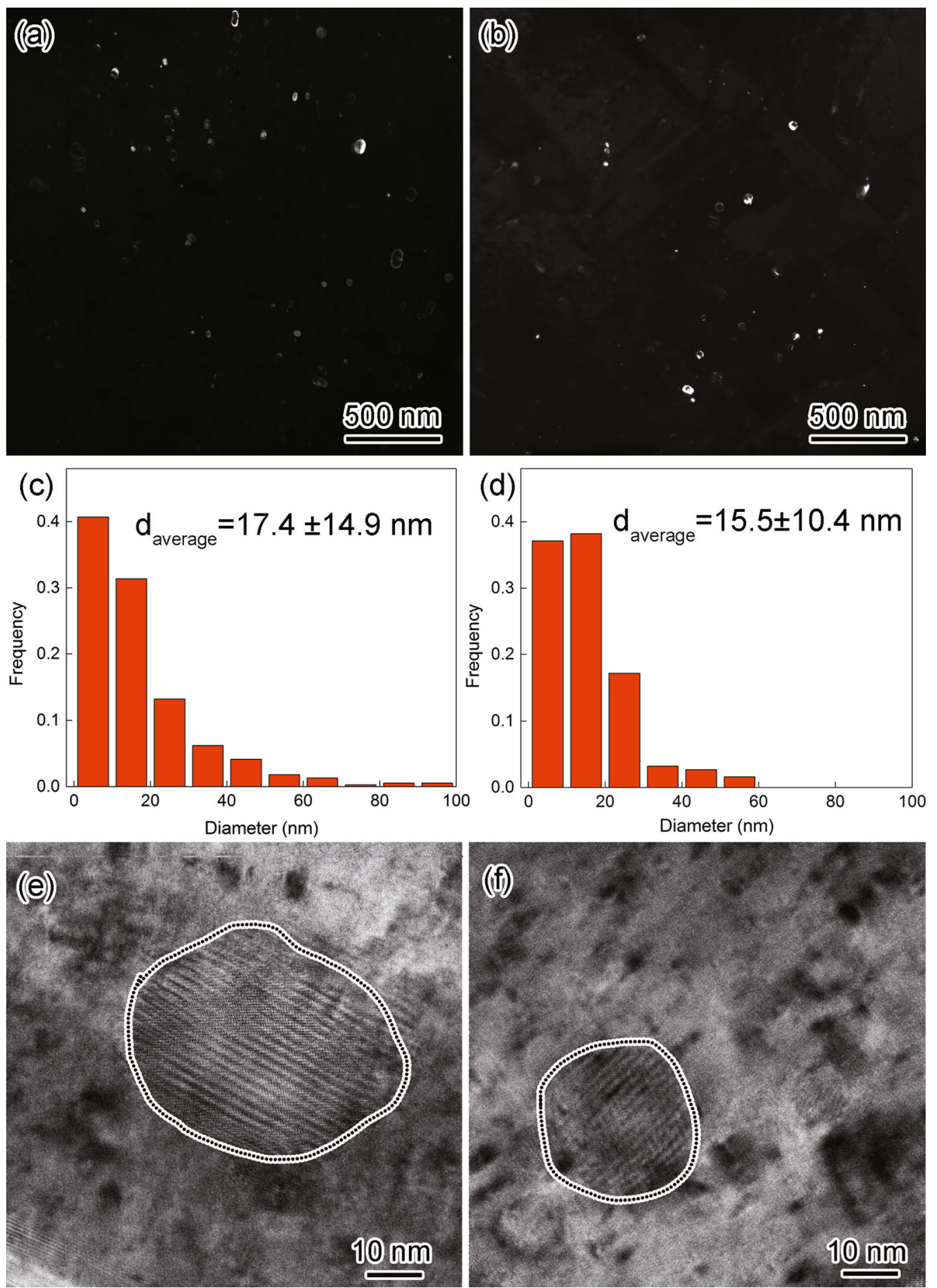

Fig. 5 a-f TEM images of $\mathrm{Cu}-\mathrm{Ni}-\mathrm{Si}$ alloys aged at $723 \mathrm{~K}$ for $2 \mathrm{~h}$ : dark-field images, precipitate size distribution and typical HRTEM images subjected to room temperature rolling $\mathbf{a}, \mathbf{c}, \mathbf{e}$, cryorolling $\mathbf{b}, \mathbf{d}, \mathbf{f}$, respectively

where $\Omega$ is the atomic volume, $D$ is the bulk diffusion coefficient, $C_{\mathrm{e}}$ is the equilibrium concentration at the surface of a flat interface and $\alpha$ is the capillary length determined by the particle/matrix interfacial energy. As mentioned above, cryorolling promotes the onset of recrystallization during aging process. The migration of the grain boundaries during recrystallization will inevitably change the orientation between precipitates and matrix. The loss of the orientation relationship should increase the interfacial energy and this should allow for faster coarsening. However, things are more complex in the present study. Figure 6 illustrates the SEM images of $\mathrm{Cu}-\mathrm{Ni}-\mathrm{Si}$ 

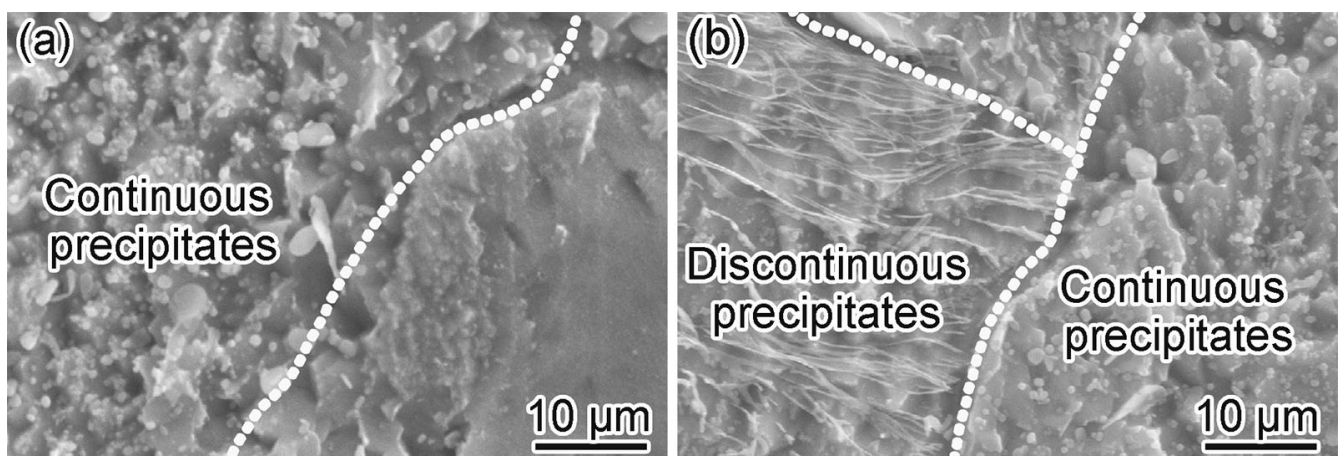

Fig. 6 SEM images of $\mathrm{Cu}-\mathrm{Ni}-\mathrm{Si}$ alloy aged at $723 \mathrm{~K}$ for $24 \mathrm{~h}$ : a RTR sample, b CR sample

alloys aged at $723 \mathrm{~K}$ for $24 \mathrm{~h}$. Typical features of overaging can be observed in $\mathrm{Cu}-\mathrm{Ni}-\mathrm{Si}$ alloys under both conditions. For RTR samples, continuous precipitates ranging from tens to hundreds of nanometers distribute uniformly in copper matrix. In addition to continuous precipitates well over a hundred nanometers, coarse discontinuous precipitates in strips are also observed in CR samples, the dimension of which exceed micrometers. The formation of discontinuous precipitates is known to be driven by the reduction in matrix/precipitate surface energy and matrix/precipitate strain energy [35]. Grain boundary cells consisting of alternate lamellae of a precipitate phase and solute-depleted matrix form during discontinuous precipitation, which accompanies the grain boundary migration into a supersaturated matrix [36]. Discontinuous precipitates nucleate at the edge of grain and form in nodules whose growth then proceeds inwards from the grain boundaries [37]. During the discontinuous precipitation, the redistribution of solute is independent on volume diffusion of matrix but dependent on diffusion of interface [38]. For CR samples, the migration of grain boundaries during aging facilitates the nucleation of discontinuous precipitates at grain boundaries, hence promoting discontinuous precipitation. For RTR samples, little evidence of recrystallization can be found (Fig. 3f). The formation of continuous precipitates reduces the matrix supersaturation and hinders the migration of the high-angle grain boundaries which are necessary for growth of discontinuous precipitates [37]. As a result, the discontinuous precipitation is suppressed.

\section{Conclusions}

The precipitation of $\mathrm{Cu}-\mathrm{Ni}-\mathrm{Si}$ alloys is significantly accelerated by cryorolling, which is confirmed by in situ synchrotron diffraction analysis. Cryorolling increases the dislocation density of $\mathrm{Cu}-\mathrm{Ni}-\mathrm{Si}$ alloys, promoting the precipitation process through higher number density of heterogeneous nucleation sites. The enhanced nucleation of precipitates accelerates the depletion of supersaturation and suppresses the coarsening of precipitates in the early stage of aging. In addition, recrystallization is promoted as a result of high stored energy in cryorolled $\mathrm{Cu}-\mathrm{Ni}-\mathrm{Si}$ alloys, which facilitates the formation of discontinuous precipitation in the late stage of aging.

Acknowledgements The authors gratefully acknowledge the supports of National Key Research and Development Program of China (No. 2017YFA0403803), the National Natural Science Foundation of China (Nos. 51525401, 51774065, 51690163 and 51601028), the Dalian Support Plan for Innovation of High-level Talents (Top and Leading Talents, 2015R013). The authors thank SSRF for providing the beamtime and all the staff members of the beamline BL14B1 for technical supports during experiments.

\section{References}

[1] J. Chen, X.G. Ma, W. Yan, F. Xia, X.H. Fan, J. Mater. Sci. Technol. 30, 184 (2014)

[2] Y. Zhang, Y.S. Li, N.R. Tao, K. Lu, Appl. Phys. Lett. 91, 282 (2007)

[3] Z. Sun, C. Laitem, A. Vincent, Mater. Sci. Eng. A 477, 145 (2008)

[4] J. Hu, C.F. Dong, X.G. Li, K. Xiao, J. Mater. Sci. Technol. 26, 355 (2010)

[5] S. Suzuki, K. Hirabayashi, H. Shibata, K. Mimura, M. Isshiki, Y. Waseda, Scr. Mater. 48, 431 (2003)

[6] Y. Zhang, H.L. Sun, A.A. Volinsky, B.H. Tian, Z. Chai, P. Liu, Y. Liu, Acta Metall. Sin. (Engl. Lett.) 29, 422 (2016)

[7] M.C. Somani, L.P. Karjalainen, Acta Metall. Sin. (Engl. Lett.) 17, 111 (2004)

[8] Q. Lei, Z. Li, Y. Gao, X. Peng, B. Derby, J. Alloys Compd. 695, 2413 (2017)

[9] Q. Lei, Z. Li, T. Xiao, Y. Pang, Z.Q. Xiang, W.T. Qiu, Z. Xiao, Intermetallics 42, 77 (2013)

[10] F. Djavanroodi, A.A. Zolfaghari, M. Ebrahimi, K. Nikbin, Acta Metall. Sin. (Engl. Lett.) 27, 95 (2014)

[11] R. Monzen, Y. Takagawa, C. Watanabe, D. Terada, N. Tsuji, Proc. Eng. 10, 2417 (2011)

[12] A.Y. Khereddine, F.H. Larbi, H. Azzeddine, T. Baudin, F. Brisset, A.L. Helbert, M.H. Mathon, M. Kawasaki, D. Bradai, T.G. Langdon, J. Alloys Compd. 574, 361 (2013)

[13] S.M. Dasharath, S. Mula, Mater. Sci. Eng. A 675, 403 (2016)

[14] Y.M. Wang, M.W. Chen, F.H. Zhou, E. Ma, Nature 419, 912 (2002) 
[15] G. Anand, K. Barai, R. Madhavan, P.P. Chattopadhyay, Mater. Sci. Eng. A 638, 114 (2015)

[16] R.G. Li, H.J. Kang, Z.N. Chen, G.H. Fan, C.L. Zou, W. Wang, S.J. Zhang, Y.P. Lu, J.C. Jie, Z.Q. Cao, Sci. Rep. 6, 20799 (2016)

[17] T. Konkova, S. Mironov, A. Korznikov, G. Korznikova, M.M. Myshlyaev, S.L. Semiatin, J. Alloys Compd. 648, 858 (2015)

[18] S. Mula, S. Dasharath, Mater. Des. 99, 552 (2016)

[19] T.Y. Yang, W. Wen, G.Z. Yin, X.L. Li, M. Gao, Y.L. Gu, L. Li, Nucl. Sci. Techol. 26, 5 (2015)

[20] A.P. Hammersley, Solid State Ferment. Bioreact. 8, 1 (1997)

[21] C. Yu, B. Aoun, L.S. Cui, Y.N. Liu, H. Yang, X.H. Jiang, S. Cai, D.Q. Jiang, Z.P. Liu, D.E. Brown, Y. Ren, Acta Mater. 115, 35 (2016)

[22] G.K. Williamson, W.H. Hall, Acta Metall. 1, 22 (1953)

[23] C.L. Zou, H.J. Kang, W. Wang, Z.N. Chen, R.G. Li, X.X. Gao, T.J. Li, T.M. Wang, J. Alloys Compd. 687, 312 (2016)

[24] Y. Zhang, N.R. Tao, K. Lu, Acta Mater. 56, 2429 (2008)

[25] T. Konkova, S. Mironov, A. Korznikov, M.M. Myshlyaev, S.L. Semiatin, Mater. Sci. Eng. A 585, 178 (2013)
[26] P. Liu, B.X. Kang, X.G. Cao, J.L. Huang, B. Yin, H.C. Gu, Acta Metall. Sin. (Engl. Lett.) 12, 273 (1999)

[27] H.S. Zurob, C.R. Hutchinson, Y. Brechet, G. Purdy, Acta Mater. 50, 3077 (2002)

[28] B. Dutta, C.M. Sellars, Mater. Sci. Technol. 3, 197 (1987)

[29] T. Hu, J.H. Chen, J.Z. Liu, Z.R. Liu, C.L. Wu, Acta Mater. 61, $1210(2013)$

[30] H.S. Zurob, Y. Brechet, G. Purdy, Acta Mater. 49, 4183 (2001)

[31] K.C. Russell, Adv. Colloid Interface Sci. 13, 205 (1980)

[32] G. Sundar, J.J. Hoyt, J. Phys. Condens. Matter 4, 4359 (1992)

[33] J. Huang, M. Meyer, V. Pontikis, Phys. Rev. Lett. 63, 628 (1989)

[34] J.J. Hoyt, Acta Metall. Mater. 39, 2091 (1991)

[35] F. Findik, J. Mater. Sci. Lett. 17, 79 (1998)

[36] F. Shi, L.J. Wang, W.F. Cui, C.M. Liu, Acta Metall. Sin. (Engl. Lett.) 20, 95 (2007)

[37] J.D. Robson, Acta Mater. 61, 7781 (2013)

[38] Y.C. Tang, Y.L. Kang, L.J. Yue, X.L. Jiao, Acta Metall. Sin. (Engl. Lett.) 28, 307 (2015) 